\title{
TUBERCULOSIS Y EMBARAZO
}

Doctores Hernando Amaya-León * y Jorge Flórez-Arzayiis :*

Cuando se habla de Tuberculosis y Embarazo, surgen dos posiciones como lo anota muy bien Blank - 1 -

a) Se trata de una paciente estéril por una afección tuberculosa genital, sometida a tratamiento y que en un momento determinado queda embarazada;

b) Paciente embarazada con una tuberculosis pulmonar o extrapulmonar, activa o inaparente, tratada o nó con antimicrobianos específicos.

De la primera condición, referente a Tuberculosis Genital Femenina propiamente dicha, tratamos en nuestra ponencia del V Congreso Colombiano de Obstetricia y Ginecología -2-, y no es el propósito de este trabajo.

Es el segundo temario el que intentamos analizar; y nos referimos a tuberculosis pulmonar. De la extrapul-

* Jefe del Departamento de Obstetricia y Ginecología de la Facultad de Medicina, Universidad Nacional, Bogotá, Colombia.

*: Del Departamento de Obstetricia y Ginecología del Hospital Militar, Bogotá. Jefe del Servicio de Obstetricia y Gine. cología. Hospital Sanatorio Santa Clara. monar, no encontramos en nuestra c?suística sino dos enfermas, una linfática y otra meningítica, y que por ser casos de excepción, no nos merecen relato especial.

En países como el nuéstro, en vía de desarrollo, la TBC en todas sus formas y en especial la pulmonar, constituy: un serio problema sanitario y social.

El aumento de la tasa de población en Colombia ha demostrado ser por otra parte un factor de notable importancia, ya que las cifras encontradas en el último censo demuestran ratas de natalidad impresionantes.

Ante estos hechos evidentes, tenemos que suponer con todo acierto, que el número de futuras madres afectas de tuberculosis debe ser muy alto, y que el índice de casos sometidos a control médico adecuado es bajo en relación a la posible población infectada.

Los autores de este informe hemos sido médicos encargados de la Jefatura del Servicio de Obstetricia y Ginecología del Hospital Sanatorio Santa Clara en Bogotá, el uno (HAL) como fundador de la dependencia en 1950 hasta 1952 (y desde 1946 como ginecólogo), y el otro (JFA) desde 1960, 
quien ha atendido el mayor número de casos que se presentan.

Nuestro deseo es revisar los resultados obtenidos en nuestra casuística, tratar de obtener comparaciones con estadísticas foráneas y marcar una serie de pautas que esperamos sean de utilidad a los especialistas que afronten problemas de naturaleza similar.

\section{Material}

Se revisan los casos tratados en el Hospital Sanatorio Santa Clara de Bogotá de 1950 a 1965 .

La revisión se discrimina así:

Cuadro Nọ 1.

Anotándose que esto hace referencia a las gestaciones posteriores a su diagnóstico de tuberculosis pulmonar; luego haremos los comentarios pertinentes.

La gravidez en general se expresa así:

Cuadro Nọ 2.

En cuanto a edad:

Cuadro Nọ 3.

Observándose que más de un $50 \%$ se agrupan entre los 21 y 30 años, lo cual es compatible con la época reconocida de mayor fertilidad en la mujer.

Sobre la forma de terminación del embarazo, considerados el número total de casos:

Cuadro $\mathrm{N}^{\circ} 4$.

O sean 6 abortos y 35 partos prematuros, con una incidencia del $1.9 \%$ y $11.2 \%$ respectivamente. En cuanto a prematurez teniendo como punto de referencia el niño según su peso, se mencionará en el capítulo correspondiente.

Este índice de partos prematuros está en los límites usuales al compararlo con hospitales obstétricos que atienden personal de igual condición socioeconómica. Los abortos merecerán un análisis especial.

\section{Incidencia de tuberculosis en concomitancia con gestación}

No existe en nuestro país estadísticas al respecto.

Sospechamos una incidencia importante, por cuanto los casos detectados de TBC pulmonar aumentan año tras año, y es bien sabido que la enfermedad es más probable en los años de mayor actividad genital y procreativa del ser humano. Por otra parte, si en países como Estados Unidos de Norteamérica se calculan alrededor de 35.000 casos de embarazos en mujeres tuberculosas al año, en donde el índice de desarrollo y productividad está en la avanzada de las naciones de alto nivel cultural y económico, hay que imaginar que en Colombia esa tasa de frecuencia debe ser notoriamente alta.

Un índice muy orientador sería la búsqueda de la TBC pulmonar en Hospitales obstétricos. En efecto, en el Instituto Materno-Infantil de Bogotá, unidad perteneciente al Departamento de Obstetricia y Ginecología de la Universidad Nacional, se practicó foto-ro- 
entgenograma de rutina en la consulta prenatal durante casi 10 años; por desgracia ese material fue destruído y no pudimos encontrar referencia sino a los 2 últimos años de investigación, de julio 1958 a julio 1960 , con estos datos: De un total de 1961 estudios radiológicos practicados en la consulta prenatal fueron confirmados 15 casos de TBC pulmonar, lo cual daría un índice de positividad del $0.76 \%$.

$\mathrm{Si}$ bien este muestreo es importante desde el punto de vista estadístico y demostraría un índice de correlación entre tuberculosis y embarazo muy similar o inferior al que conocemos de USA., no estamos muy seguros que ésto corresponda a la realidad; esta duda nos nace de que los servicios de estadística, hoy bastante mejorados, en esa época tenían fallas importantes tanto en la recopilación de los datos como en la forma de tabularlos.

En las memorias del Ministerio de Salud Pública no hay datos a este respecto.

Revisando estadísticas oficiales de 1964, hay algunos datos que son de importancia:

Indice de TBC en población examinada: $2.16 \%$.

Indice en mujeres de 14-44 años: $1.1 \%$.

Estas cifras nos parecen dudosas de expresar la realidad nacional, pues en un país de 17 millones de habitantes, un total de 616.000 estudios radiológicos en 1 año no cubren ni el 5\% de la población total $\mathrm{y}$ no pueden ser su- ficientes para dar ilustración adecuada. Y estas cifras más bajas que las encontradas en países desarrollados, no pueden ser de excepción.

A propósito, recordamos algunas estadísticas extranjeras: Selikoff y col. -3-, del Mt. Sinai de New York, entre 1953 y 1956 , encuentran el $3.4 \%$ de casos de TBC pulmonar en su consulta prenatal; Bickerstaff y col. - 4- en más de 3.500 controles fotofluoroscópicos encuentran una positividad comprobada del 1.2\%; en el New York Lying-in Hospital, Schaeffer y col. - 5- en una revisión de 5 años (1952-1956) relatan una incidencia del 1.5-2\% de todas las admisiones en consulta prenatal; Reid y Caton -6consideran que el $2-3 \%$ de todas las embarazadas padecen tuberculosis pulmonar; Donald -7- anota en su libro que ". . las pacientes con tuberculosis pulmonar activa a menudo son perversamente fértiles...", indicando así su notable frecuencia en Inglaterra.

Estos datos de incidencia en países de notable desarrollo, nos hacen dudar mucho de la realidad del muestreo que hemos mencionado en nuestro medio.

Hoy, de nuevo nos surge una inquietud: En muchos hospitales, el de San Juan de Dios de Bogotá entre otros, obligaban al estudio sistemático radiológico de tórax en las pacientes embarazadas; luego, surgió la violenta reacción a esta medida en consideración a los efectos nocivos en las gonadas maternas y en los tejidos en formación del feto. Y lo real es que en la actualidad hay un rechazo casi universal a 
esta medida investigativa en el preparto; y la duda que nos asalta, es si realmente este peligro, no bien definido, de irradiación a través de una radiografía pulmonar, compensa el no descubrir a tiempo una tuberculosis activa que como hemos visto tiene una posible incidencia nada despreciable. Creemos que debemos meditar y revaluar este importante interrogante.

\section{Cuidados prenatales \\ en la tuberculosis}

Podríamos condensar las opiniones en 3 tendencias:

I. Considerar el embarazo como un proceso fisiológico que no beneficia ni empeora la enfermedad; Schaeffer y co!. - 8 - son de esta opinión.

II . Mirar la tuberculosis como entidad primaria, y al embarazo como complicación; para Skom y Gerbie -9- este concepto es fundamental.

III. Pensar en el embarazo como entidad primordial y en la tuberculosis como una complicación; era en realidad el punto de vista de los antiguos, cuando la lucha antituberculosa no pasaba del reposo y cura de aguas y clima.

Para nosotros, este problema doctrinario se debe resolver según el caso y sus tratamientos previos. Es decir, que en enfermas descuidadas o ignoradas hasta el momento del parto, el concepto III, el antiguo, sigue siendo una rea- lidad; y ahí, la tuberculosis es ciertamente una complicación, y muy grave. Así, en el IMI, revisando de julio 1958 a diciembre 1964, se encuentran 45 casos diagnosticados de TBC pulmonar, de los cuales 8 no tuvieron controles previos ni tratamiento adecuado; de éstos, 2 murieron en el puerperio inmediato, y en total dieron a luz 5 mortinatos; proporciones muy diferentes a los casos de Santa Clara, éstos vistos y tratados en su gran mayoría a su debido tiempo.

\section{Cuadro $\mathrm{N}^{\circ} 5$.}

$\mathrm{Y}$ anotamos que lograr un $92 \%$ de contro'es prenatales es cifra que no soñamos en otras instituciones hospitalarias de buena calidad.

Por ello, debemos releer a Falls -10_, cuando recordamos a Osler y a Dubois (1907), decían: "una mujer tuberculosa podría tener un hijo con seguridad, posiblemente un segundo y nunca un tercero"; Bacon (1913) afirmaba que el $33 \%$ de estas mujeres no sobrevivían al primer año después del parto; Fellner (1904), Pankow (1911) y otros alemanes confirmaron que la agravación o la mortalidad de esas enfermas variaba del 40 al $75 \%$. Pues bien: $\mathrm{Si}$ esos preceptos aún son válidos para las enfermas no reconocidas ni tratadas, vimos que las cosas son hoy día totalmente diferentes.

Si la mujer embarazada es diagnosticada como una tuberculosa grave, y sabemos con Cohen y col. - 11- que las lesiones cavernosas avanzadas son las de peor pronóstico, debemos comprender el caso en el concepto II, por- 
que la $\mathrm{TBC}$ es realmente la entidad predominante y el embarazo es la complicación; la terapia debe ser todo lo intensiva necesaria, recurriendo a lo usual en tales condiciones y relegando la complicación, en este caso el embarazo, a un segundo plano. Autores como el mencionado, Thomas - 12-Rosembach y Sangemi - 13-, etc., opinan de esta manera.

Cuando la enfermedad es leve, especialmente con tuberculosis fibrocálcica o fibrótica, tratadas e inactivas ojalá por lo menos 1 año antes del embarazo, constituyen en realidad los casos para ser considerados en el criterio I; el prenatal de estas enfermas no difiere mayor cosa de las mujeres no tuberculosas embarazadas, salvo la necesidad de controles más estrictos, mayor reposo y una dietética mejor orientada; en el Hospital Santa Clara agregamos un internamiento precoz antes del parto con el objeto de observar mejor la señora y practicar quimioterapia de refuerzo. Podríamos recordar a Jentgens —4_, quien en 1959 presentó una casuística de 2.000 enfermas, divididas en dos grupos, uno sin tratamiento, con resultados significativamente iguales.

Como hecho evidente, que queremos recalcar, es que en casos de concomitancia de embarazo y tuberculosis pulmonar activa, tales enfermas deben ser tratadas con los medios antimicrobianos o quirúrgicos, como si no estuvicran gestantes.

\section{En relación a TOXEMIAS.}

Cuadro Nọ 6.

Vemos la incidencia en un $12 \%$ del total, cifra un poco menor de lo observado en San Juan de Dios, muy cerca al $20 \%$. Al factor positivo de una prenatal mucho mejor lograda, se contrapone una tendencia de la tuberculosa hacia la toxemia, en donde tal vez juegue un papel notable el "stress", algunos recambios metabólicos alterados, problemas vasculares inducidos por toxinas bacilares, etc.

Antes de cerrar este capítulo, es necesario que mencionemos, así sea con brevedad, el muy importante aspecto psico-social que representa para una futura madre el saber de un momento a otro que está tuberculosa. No es difícil imaginar el impacto que ésto significa para ella y para el hogar, en todos sus aspectos. Una dosis de optimis-mo y de psicoterapia individual y colectiva a los seres que la rodean bien llevada por el obstetra es extraordinariamente importante. El tabú de la tuberculosis sigue siendo en nuestro medio, y en todas las capas sociales, algo muy difícil de erradicar de un momento a otro: l'evar el convencimiento de que la enfermedad no tiene ya la evolución de antaño, que los medios terapéuticos son muy eficaces, que no todo el que toque a una enferma sale contagiado, etc., es programa para el médico encargado del caso, antes de disponer el internamiento de la scñora en el hospital especializado. 


\section{Aspectos terapéuticos}

En las líneas anteriores queda establecido el principio fundamental de la importancia del reconocimiento rápido de la TBC, el tratamiento instituído a la mayor brevedad y el control estricto del embarazo.

En principio, en enfermas portadoras de lesiones activas, el embarazo no puede ser recomendado y debe proscribirse hasta por lo menos pasado e! primer año de inactividad, luego de tratamientos adecuados.

Si una tuberculosa activa queda embarazada, debe ser hospitalizada de inmediato y puesta en reposo y sometida al tratamiento intensivo sin tener en cuenta la época de la gestación.

En este momento, la paciente es del tisiólogo y el obstetra es apenas su colaborador; claro está que se constituye de inmediato un trabajo de equipo, con cirujanos torácicos, dietistas, laboratoristas, etc.; pero el tisiólogo es la figura central.

Considerado así el caso, no debemos intentar nosotros los esquemas terapéuticos, ya que constituyen labor del especialista en tuberculosis pulmonar; no podemos ignorar, claro está, que la estreptomicina, la isoniacida $y$ el PAS, son los pilares básicos de las drogas bacteriostáticas; sus dosis e intensidad son conocidas, y en parte ya mencionadas en nuestro trabajo sobre terapéutica en Tuberculosis Genital Femenina - 16-, ya que en materia de terapia médica, la tuberculosis se ataca en forma similar cualquiera que sea su localización; la etionamida y la cicloserina son auxiliares de ocasión. De todas maneras, hasta el momento aquellas son las drogas mejores, pero esperamos el hallazgo de bactericidas de acción directa y de efectividad a menor tiempo, ya que los tuberculostáticos actuales no pueden de por si ser garantía de curación definitiva, y el tiempo de su empleo continúa siendo grave problema socio-económico.

En cambio, sí es de vital importancia para el obstetra el saber los posibles efectos de las drogas mencionadas sobre el feto, y más sabiendo que hay insinuaciones de algunos autores sobre toxicidad. Uno de nosotros - 17- presentó en 1953 una serie de enfermas embarazadas tratadas con isoniacida, con resultados magníficos y sin tropiezos fetales; Lowe - 18 - reporta en 1964, 74 casos tratados con combinaciones de las drogas mencionadas, sin lograr demostrar ningún efecto teratogénico; y de paso, tampoco comprobar lo sugerido por Mc Donald en 1961 de que los niños nacidos de madres con historias de tuberculosis mostraban exceso de defectos congénitos; en nuestra serie, tan solo un niño presentó polidactilia, no habiendo otros reportes de las salas de Pediatría a este respecto. En los casos que presentamos en este trabajo, se hará un análisis posterior respecto a los niños nacidos, pero podemos adelantar el ningún efecto teratogénico de las drogas en los muchos casos en que se usaron en forma sistemática y continuada. 
No podemos dejar de mencionar el hecho, muy importante, de que después de muchas dudas iniciales, hoy se acepta en forma universal que todas las medidas de terapéutica quirúrgica pulmonar deben ser tomadas, sin tener en cuenta el embarazo: toracoplastias, lobectomías, resecciones segmentarias, y aún pneumonectomías son permisibles y deben ser ejecutadas en las condiciones de rutina, siguiendo los cursos habituales de preparación tuberculostática pre y postoperatoria.

Los informes de Corner y Nessbitt -19-, Schaeffer y Epstein -20-, Folsome -21-, son perfectamente claros a ese respecto; Laros - 22en Holanda, en 64 mujeres con tuberculosis pulmonar sometidas a pneumonectomía y con 74 embarazos, obtuvo evolución normal y niños vivos en 70 casos; muy recientemente, Schaeffer y Brander - 23- ponen de manifiesto en una amplia revisión de embarazadas luego de operaciones torácicas mayores entre las cuales había 56 tuberculosas con 83 intervenciones, el buen desarrollo de la gestación, la poca influencia de ésta en el normal curso de la TBC, y la ninguna peligrosidad para los niños de esas madres. En nuestras 237 enfermas.

\section{Cuadro Nọ 7.}

Es posible apreciar que los resultados son comparab'es a los mencionados, y los procedimientos operatorios se cumplieron sin afectar el curso del embarazo ni el porvenir de esos niños.
En cuanto a colapsoterapia, pneumotorax y pneumoperitoneo, etc., ha perdido mucho terreno en el campo de la buena tisioterapia; en lo que respecta a nuestra actividad, debemos relatar el hecho que hasta 1957 se hacía de rutina pneumoperitoneo en el inmediato post-parto con el objeto de evitar descomprensión brusca del tórax; desde esa fecha se suspendió del todo tal medida, y hemos comprobado que ningún cambio se observó en las pacientes desde entonces, evitándose eso sí, los peligros inherentes a tal procedimiento; embolias gaseosas, infección, etc.; sin embargo, muchos autores aun insisten en tal medida que para nosotros, hoy en día, es casi por completo inoperante.

\section{Patología asociada}

Denominamos así aquel grupo de enfermedades importantes que nos lla-maron la atención al sobreagregarse a la tuberculosis pulmonar, y que requirieron atención especial.

\section{Cuadro Nọ 8.}

En donde se destạcan las tres primeras entidades.

Fue nuestra intención hacer estudios comparativos y analíticos del factor Anemia, tan importante en nuestro medio. En el caso presente se identificó en más del $37 \%$, cifra que nos parece alta y a la que debe contribuír en buena proporción la concomitancia de embarazo, tuberculosis y razones socioeconómicas evidentes: Hiponutri- 
ción, carencia de hierro por mala absorción, etc.; pero al no poseer estudios definidos y concretos sobre Anemias y Embarazo en nuestro país, nos pareció azaroso entrar en especulaciones imaginativas. El hecho evidente es que su proporción es muy importante y que sin duda contribuyó a desmejorar el peso de los recién nacidos a término de estas madres.

Se procuró tratar estos estados de anemia con toda intensidad, y en algunas enfermas se llevaron transfusiones sanguíneas a intervalos; pero se recuerda que en estas mujeres, saturadas de drogas tuberculostáticas y con tanta propensión a náuseas e intolerancias digestivas, la administración de hierro y otros preparados no siempre es bien tolerada.

La sífilis, en 14 casos, es un índice propio a las clases menos favorecidas, en donde la desnutrición y la carencia de higiene corren parejas a un inadecuado conocimiento de los problemas profilácticos médicos. De lógica, fueron tratados con toda la intensidad necesaria, pero estos casos contribuyeron al capítulo de ábortos y muertes fetales tempranas.

Las cardiopatías se asocian con alguna frecuencia a la TBC pulmonar; su evaluación y tratamiento deben ser analizadas con periodicidad por el equipo médico encargado de la enferma.

Las otras condiciones, muy ocasionales, no merecen revisión especial.

En términos generales, las entidades patológicas asociadas a tuberculosis pul- monar en embarazadas deben ser reconocidas y tratadas con oportunidad, pues agravan un pronóstico de por sí comprometido.

\section{Consideraciones al parto}

Ya en el trabajo del parto, 4 puntos fundamentales nos parecen deben ser considerados:

1. Mínima sedación y analgesia.

2. Anestesia tipo regional.

3. Acortamiento del $2^{\circ}$ período.

4. Posibilidad de medidas quirúrgicas.

En principio, es nuestra doctrina no alterar los postulados usuales en la atención del parto normal. En el caso de la tuberculosa embarazada, tan solo recalcamos en pequeñas variantes.

\section{Sedación y Analgesia.}

En la práctica obstétrica en nuestro país, en términos generales, no somos aficionados a exagerar en este aspecto; y mucho menos en los medios hospitalarios, en donde las condiciones materiales son siempre restrictivas.

El uso de meperidina, algunos barbitúricos y tranquilizantes, están autorizados en este tipo de pacientes, pero procurando hacerlo en dosis pequeñas. En esta forma las hemos indicado en nuestro grupo presentado, así.

Cuadro Nọ 9

En este cuadro hay dos comentarios que hacer: a) El empleo de Tricloro- 
etileno F. Br. ("Trilene") en una época en forma continuada y con muy buenos resultados, sin complicaciones posteriores; ésto no se aconseja en casos de TBC activa, pero no es contraindicación absoluta; hoy no lo empleamos, sin ser sus detractores; b) Ta! vez si se hace una estricta comparación con embarazadas de hospitales obstétricos generales, se nos puede argüír que hemos empleado mayor analgesia y sedación que en estas instituciones; cabe una explicación, y es que para la paciente tuberculosa el momento del parto es motivo de indudable angustia y "stress" emocional, aunque se haya intentado una psicoterapia preparatoria adecuada; y ayudarla en este sentido, es importante.

\section{Anestesia.}

En términos generales, debe preferirse la regional: Bloqueo pudendo, "en silla", etc., por razones que nos parecen obvias, y en especial cuando la paciente es tuberculosa activa; sin embargo, no hay contraindicación absoluta en emplear inhalantes, en dosis pequeñas y fraccionadas, aunque el anestesiólogo debe decidir la conducta en cada caso.

\section{Acortamiento del $2^{\circ}$ período.}

En general, debe procurarse que la duración del trabajo del parto sea lo más corto posible. En nuestra casuística encontramos:

Cuadro Nọ 10

Lapsos que pudiéramos llamar en límites razonables,
Hemos procurado refuerzo o conducción del parto con Pitocín en dextrosa en dosis y métodos habituales cuando la indicación obstétrica lo requería; se practicó en 27 casos, sin complicaciones.

Autores recomiendan, y así 1o practicamos, episiotomía y fórceps de desprendimiento para acortar el $2^{\circ}$ período del parto, en el cual esfuerzos inmoderados pueden ocasionalmente reactivar una TBC inaparente o agravar una en estado cavitario.

4. Posibilidad quirúrgica.

Es lógico que las indicaciones obstétricas puras de cesárea no tienen discusión y no las analizamos. En nues-tras enfermas vemos:

\section{Cuadro Nọ 11.}

En donde tan solo se consideró necesario hacer 2 cesáreas por causa pulmonar: enfermas cavitarias avanzadas, con episodios de hemoptisis severos, y en quienes un esfuerzo de parto se consideró francamente peligroso. Esta posibilidad puede ser tenida en cuenta en trabajos muy prolongados, con especial referencia a primíparas con tuberculosis activa; en estas condiciones, es realmente el equipo médico (obstetra, tisiólogo, internista, anestesiólogo, etc.) quienes deciden el manejo de estos casos.

\section{Aborto en tuberculosas embarazadas}

Dos aspectos queremos discutir en este capítulo: 
1. Incidencia en general.

2. Aborto terapéutico.

En cuanto a lo primero, encontramos en nuestro estudio un total de 6 abortos, que comparados en 313 casos, da una incidencia global de $1.9 \%$. En los servicios obstétricos del hospital San Juan de Dios, esta incidencia es muy aproximada al $20 \%$.

Esta diferencia a favor de las tuberculosas, la podríamos explicar por: a) Mejor y más comp'eta atención prenatal, que como vimos, en Santa Clara se logró en un $92 \%$ y en cambio en San Juan de Dios no se ha podido siquiera aproximar a la mitad de esa cifra; b) El aumento nítido del aborto provocado en las clases menos favorecidas, factor que no parece ser usual en el caso de enfermas tuberculosas embarazadas, ya sea por temor o quizá por ser mujeres en general con menor multiparidad que las no enfermas; ésto podría ser influído por amenorreas y anovulaciones en casos avanzados, larga reclusión en distintas etapas de terapéutica, anticoncepción recomendada, etc.; c) No parecen existir elementos tóxicos o inmunológicos provenientes del B. de Koch que afecten directamente al embrión.

Estas consideraciones nos permiten suponer que, por lo menos, el aborto no es influído en forma importante por la infección tuberculosa "per se".

Refiriéndonos al aborto terapéutico, este tema ha sido ampliamente debatido en todos los círculos científicos. En nuestro medio nunca se intentó por razones morales y legales.

Sin entrar en mayores disquisiciones, podemos asegurar que hoy se considera medida inútil, y aún más peligrosa; además, con la terapia tuberculostática moderna, ni aún en casos muy avanzados, esta medida abortiva tiene sentido práctico y debe ser eliminada como procedimiento terapéutico.

\section{Tuberculosis de la placenta}

Algunos autores han reportado excepcionales casos de placentas con infección tuberculosa.

En 1951, se inició en nuestra unidad de Santa Clara un estudio histológico investigativo a este respecto; de un total de 76 placentas enviadas, la sección de Patología no encontró alteración tuberculosa franca en una revisión cuidadosa de las piezas. Los hallazgos importantes fueron:

Membrana con inflamación de tipo inespecífico $\ldots \ldots \ldots \ldots \ldots$

Zcnas de infarto .......... 4

Metaplasia escamosa de la membrana amniótica ......... 1

Fibrosis difusa del parenquima . . 1

Placenta anormalmente aumentada de tamaño con lesión "fibroide" no clasificada ........... !

En los casos positivos hallados en la literatura, parece que lo frecuente es el desarrollo de trombos bacilares en los espacios venosos de las vellosidades, siendo su origen dẹterminado 
en un posible paso de bacilemia tuberculosa originado en un foco pulmonar activo.

Es de pensar que el hallazgo histológico es difícil y se necesitarían estıdios seriados múltiples, que en un órgano tan voluminoso como la placen. ta, haría esa revisión muy dispendiosa. Por esto pensamos que, si se adiciona un estudio bacteriológico de maceración del órgano, con las técnicas que actualmente se siguen en el Instituto Nacional de Salud y ya reportadas en trabajos anteriores, la investigación se facilita y es más completa.

Como en 1951 y subsiguientes, estas técnicas no eran viables, los estudios en los casos anotados quedaron incompletos en ese sentido; pero una nueva etapa investigativa podría ser intentada.

\section{Puerperio}

De acuerdo con la mayoría de los interesados en este tópico, esta etapa obstétrica es muy importante en la tuberculosa. Porque es de suponer que en mujeres en condiciones de por sí precarias, se agregan factores como hemorragia, "stress" del trabajo del parto, cambios metabólicos y hormonales notorios, y hasta una posible sepsis, el deterioro general y pulmonar puede ser grave. Blake -24-, Rist -25-, Hedvall -26-, Schaeffer y col. $-27-$, en sus reportes analizan estos factores.

$\mathrm{Ya}$ anotamos como en enfermas no controladas o ignoradas de su TBC, al- gunas mueren en el puerperio; otras lo hacen en el curso de pocos meses.

Pero, el acuerdo unánime actual es, de que si la tuberculosa es debidamente cuidada y tratada en el prenatal, se llevan a cabo algunas medidas en el parto y se vigila estrechamente el puerperio, la evolución de la enfermedad es muy similar en la mujer tuberculosa con embarazo en comparación con la que no lo está. El trabajo de Szalay y Lehoczky -28 - en 1961 sobre 859 enfermas tuberculosas es muy importante, llegando a la conclusión de que no hubo diferencia substancial entre embarazadas, puerperas y no embarazadas, anotando que en $0.3 \%$ de gestantes y el $2.2 \%$ de las puérperas hubo deterioro o muerte, igual que en los grupos controles.

Nuestra casuística demuestra resultados similares.

\section{Cuadro Nọ 12.}

La conducta en las puerperas tuberculosas puede resumirse así:

1. Si la enferma es tuberculosa activa, se reinician las medidas terapéuticas de inmediato, y continúa su internación en el hospital hasta el momento que determinen los tisiólogos; si hubo pérdida de sangre importante en el parto, se repondrá con todo vigor y se cuidará con todo esmero para evitar infecciones, etc.

2. Con las inactivas, el problema es a veces más difícil en cuanto a manejo. Se mantienen en reposo y observación en el hospital durante 15 días 
practicando tratamiento bacteriostático intensivo, de "consolidación", y luego van a su casa; por dos motivos: porque la señora se siente muy bien y tiene que atender su hogar, y lo segundo porque el hospital necesita esos cupos para casos avanzados. Y ciertamente, en esa época de mayor trajín, con recién nacido, sin ayuda pues se trata de gente de escala socio-económica baja, sus condiciones genera!es pueden desmejorar notoriamente y venir reactivaciones de su problema pulmonar; ésto ha sucedido en un número pequeño de enfermas, aunque las proporciones parecen ser no muy distantes de los casos de enfermas no puérperas.

De todas maneras, aunque no sea de esperar complicaciones severas en el puerperio de tuberculosas, si han sido bien tratadas, se aconseja una observación más constante que en los puerperios corrientes.

\section{Porvenir del niño nacido de madre tuberculosa}

Iniciamos este capítulo diciendo que la tuberculosis congénita es excepcional; no hay dos centenares de casos descritos en la literatura mundial.

Al parecer existen 2 mecanismos probables:

a) Infección por vía hematógena, a través de la vena umbilical, y causando en tales fetos prematurez; se comprende que este efecto agregado a la tuberculosis pone al recién nacido en pésimas condiciones, y muy difícil sobrevida.

b) Infección por aspiración de líquido amniótico infectado, en el momento de nacer; realmente se trata de casos exóticos, sin mayor importancia.

En nuestro grupo, no hay un sólo caso de tuberculosis congénita.

Al analizar el peso del recién nacido:

\section{Cuadro Nọ 13}

Encontramos índices bastante satisfactorios para nuestro medio.

Lo mismo podríamos decir de los mortinatos y la mortalidad neonatal, siendo estos casos de mayor frecuencia en las tuberculosas activas de menor tiempo de tratamiento y con mal estado general; pero en un sentido global de análisis, estos índices son realmente favorables.

El porvenir del niño nacido de madre tuberculosa en términos generales, es magnífico; se entiende claro está, de las enfermas sometidas a un buen prenatal y atendidas en su parto en forma adecuada.

Ya vimos que el aborto es raro; la prematuridad, en límites comunes; hay diferencias en comparación con series de hospitales generales obstétricos. Cuando se presentan, se asocian generalmente a madres en malas condiciones generales, desnutridas, muy anémicas, etc., entidades que no son propias únicamente a la tuberculosis; si estos casos se corrigen, los niños tienen toda la oportunidad de llegar a 
término y nacer con peso adecuado y buenas condiciones generales.

Aun más: el aspecto físico de la mayoría de los chicos en las salacunas de estas instituciones es muy bueno; quizá el buen prenatal, mejor dietética, vitaminoterapia y el reposo de las madres favorecen a esos niños en relación a grupos de madres no enfermas.

Datos importantes: esos niños se aislan inmediatamente después de nacidos, no reciben alimentación materna, son vacunados en los primeros días, $y$ permanecen en las sala-cunas al cuidado de la Liga Antituberculosa y bajo supervisión de expertos pediatras hasta el momento en que se considere que la madre es apta para continuar su crianza en el hogar.

\section{Anotaciones sobre influencia de la gestación en la tuberculosis pulmonar}

Habiendo intentado un análisis sobre efectos de la TBC en el embarazo, parto, puerperio y recién nacido, debemos ahora para terminar, contemplar la influencia del estado grávidopuerpera! en la tuberculosis pulmonar.

No es necesario acudir a especulaciones pseudocientíficas para suponer que los postulados de diagnóstico rápido y precocidad e intensidad de tratamiento son aspectos definitivos en este pronóstico.

En cuanto al tiempo de evolución, este cuadro nos facilita el dato con relativa exactitud, ya que existen errores apreciativos imposibles de evitar;
Cuadro No 14.

Estos números nos explican en parte el por qué la mayoría de nuestras enfermas eran consideradas activas, ya que por el tiempo de evolución, los cursos de tratamiento no habían sido suficientes en el momento de su primera consulta prenatal. A este propósito, consideramos este aspecto:

Cuadro No 15.

En donde 156 casos tenían menos de 1 año de tratamiento, o sea el $65.8 \%$; y no podría ser en dicho lapso inactivada una tuberculosis evolutiva; por este motivo, 191 de las 237 pacientes, o sea el $80 \%$ estaban activas en la primera consulta prenatal.

Estas cifras de nuestra casuística contrastan notablemente con las de autores europeos y norteamericanos; en esos trabajos, estos porcentajes están completamente a la inversa. Nuestra explicación renueva lo afirmado en el capítulo de Incidencia; nuestros mecanismos sanitarios aún no están capacitados para una búsqueda sistemática y decidida de la tuberculosis pulmonar, y casi siempre son factores accidentales los que provocan ese hallazgo; y por ello el diagnóstico no es lo suficientemente precoz para prevenir que una mujer de edad concepcional y a quien se descubre una TBC pulmonar, se procure evitar hasta donde ello sea posible el embarazo, y no permitirlo sino hasta que haya transcurrido un tiempo prudencial luego de terminar la terapia de rigor y procurando que esa señora lleve por lo menos un 
año de inactividad; todo ésto supone como mínimo 3 años de proceso.

Veamos qué sucedió en nuestras enfermas:

Cuadro No 16.

Cuadro Nọ 17.

Es decir, que a pesar de su mal estado inicial en un alto porcentaje, estos casos evolucionaron muy bien en términos generales. Nuestra explicación es la siguiente:

a) Hospita!ización inmediata al diagnóstico y tratamientos tuberculostáticos muy activos.

b) Una definida tendencia de nuestro pueblo, por su mestizaje y factores de resistencia adquirida, a que cuando enferma, si se les cuida, se nutren bien, se ponen en condiciones de defensa adecuada, responden entonces en forma increíble a la terapéutica usual. Nosotros no estamos muy seguros que en otras latitudes y con razas muy puras, al iniciar un estudio con $80 \%$ de enfermas tuberculosas activas, se logren los resultados que se aprecian en nuestras estadísticas, usando procedimientos terapéuticos similares.

Esta sorpresa que hemos tenido con varias entidades de estudio, la debemos consignar una vez más.

El hecho evidente en el análisis de nuestra casuística es que, en este grupo de enfermas, el estado grávido-puerperal no afectó la evolución de la tuberculosis pulmonar y que esa evolución fue notoriamente similar a las enfermas no embarazadas de iguales condiciones.

\section{Resumen}

Es un hecho notorio que la Incidencia de tuberculosis pulmonar en embarazadas en nuestro medio es muy baja al ser comparada con la de países de mayor desarrollo económico y cultural; ésto nos merece consideraciones que indican posibles errores en esa evaluación. Estamos convencidos de que esas cifras son mucho más considerables.

En líneas generales, la tuberculosis pulmonar ejerce un efecto nocivo sobre la gestación mucho menos importante de lo que se pensaba antaño. Con cuidados prenatales adecuados, siendo muy estricto en el análisis y tratamiento de la patología asociada, ejecutando terapéutica tuberculostática bien planeada, acudiendo a las técnicas operatorias efectuadas por personal entrenado y trabajando en equipo, no hay diferencias fundamentales en la situación obstétrica al comparar grupos de tuberculosas con otros de iguales condiciones socio-económicas no afectados de tal enfermedad.

La atención del parto no contempla variaciones substanciales de la línea regular usual en pacientes no tuberculosas. Tan solo se aconseja procurar acortar la duración del trabajo, en especial en su $2^{\circ}$ período, ser parco en el uso de drogas analgésicas y sedantes, y preferir la anestesia de tipo regional. 
En cuanto a los abortos, hay una diferencia muy a favor de las tuberculosas embarazadas; la prenatal bien controlada y la menor proporción de abortos provocados, nos explica esta situación, a primera vista muy objetable.

El puerperio debe ser estrechamente vigilado y nos parece aconsejable proporcionar tratamiento de consolidación en pacientes inactivas; las de forma activa, es obvio, deben continuar con la terapia intensiva.

Nos parece muy fayorable la situación del niño recién nacido de madre tuberculosa, si ésta ha sido tratada y vigilada como se aconseja. El aislamiento inmediato, alimentación no materna y el cuidado por expertos pediatras ponen a estos niños al abrigo de posibles problemas pulmonares o generales.

En nuestro grupo de estudio, no se observó en términos generales influencia desfavorable del estado grávidopuerperal sobre la tuberculosis pulmonar; la evolución de ésta es muy similar a la de tuberculosas no gestantes; esto está de acuerdo con las series reportadas de países europeos y americanos. Esta observación está lógica mente condicionada a la forma adecuada como se manejen estos casos.

\section{CONCLUSIONES}

1. Se analiza un grupo de 237 tuberculosas embarazadas para un total de 313 casos, vistos y tratados en el Hospital Sanatorio Santa Clara de Bogotá,
2. De los 313 casos, 265 terminaron en parto espontáneo; de las 9 cesáreas, $2.9 \%$, índice bajo de por sí, tan solo 2 fueron originadas por el factor tuberculosis.

3. El aborto en número de $6,1.9 \%$, y 35 partos prematuros, $11.2 \%$, son índices muy favorables en comparación a grupos obstétri$\cos$ de iguales condiciones socioeconómicas y personal no tuberculoso.

4. Se logró un $92 \%$ de controles prenatales adecuados en el grupo de estudio, cifra desusada en nuestro medio hospitalario.

5. La terapéutica tuberculostática y quirúrgica no difiere en nada de la rutinaria en $\mathrm{TBC}$ pulmonar.

6. Se analizan condiciones de atención del parto y manejo de estas puérperas.

7. No se hallaron casos de tuberculosis de la placenta en 78 observaciones histológicas; se recomiendan nuevos estudios con bacteriología de maceración del órgano, según técnicas ya descritas.

8. No hay evidencia de factores teratogénicos en los niños nacidos de madres tuberculosas tratadas con estreptomicina, isoniacida y PAS. Tampoco hay en el grupo observado, exceso de defectos congénitos, 
9. Se discute el porvenir del niño nacido de madre tuberculosa, siendo éste muy favorable.

10. Los índices de agravación de la tuberculosis en este grupo dc enfermas son mínimos, 2 entre 185 pacientes de un solo caso obstétrico y en 4 de varias gestaciones de un total de 52 pacientes y 128 embarazos. Esto se condiciona a la vigilancia y tratamiento adecuados.

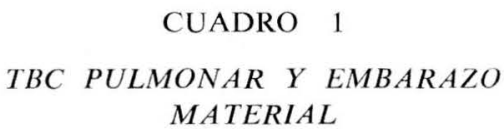

237 pacientes para 313 casos obstétricos

Con un caso obstétrico 185 pacientes para 185 casos.

Con más de un caso obstétrico 52 pacientes para 128 casos.

$$
\text { Casos }
$$

Pacientes

$\begin{array}{cl}\text { Con } & 2 \\ , & 3 \\ , & 4 \\ , & 5\end{array}$

$\begin{array}{r}36 \\ 12 \\ 1 \\ 3 \\ \hline 52\end{array}$

\section{CUADRO 2}

TBC PULMONAR Y EMBARAZO

$$
\text { PARIDAD }
$$

Sobre 237 pacientes

Pacientes

$\begin{array}{lll}\text { G. } & 1 & 33 \\ \text { G. } & 2 & 29 \\ \text { G. } & 3 & 23 \\ \text { G. } & 4 & 30 \\ \text { G. } & 5 & 36 \\ \text { G. } & 6 \text { y más } & 86\end{array}$

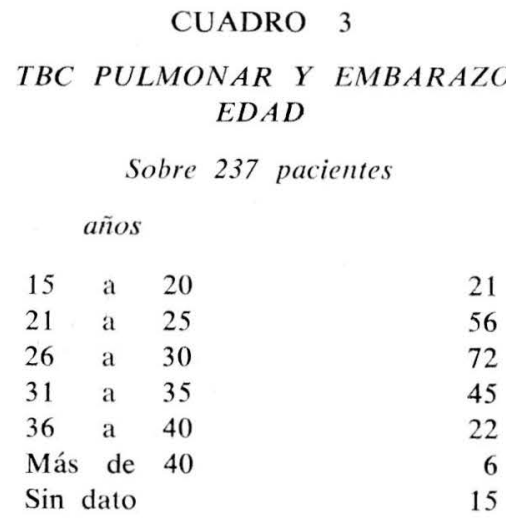

\section{CUADRO 4 \\ TBC PULMONAR Y EMBARAZO EDAD EMBARAZO}

Sobre 313 casos

\begin{tabular}{lcc}
\multicolumn{3}{c}{ Semanas } \\
- & de & 26 \\
26 & a & 31 \\
32 & a & 35 \\
36 & a & 39 \\
De & & 40 \\
+ & de & 40
\end{tabular}

Casos

\section{CUADRO 5 \\ TBC PULMONAR Y EMBARAZO PRENATAL}

Sobre 313 casos

Control prenatal 290

Sin control prenatal

$$
\text { CUADRO } 6
$$

TBC PULMONAR Y EMBARAZO TOXEMIA

Sobre 313 casos

Pre-eclampsia ................ 29

Eclampsia puerperio ............ 1

Enfermedad crónica hiper. ........ 4

Enfermedad crónica hiper. con toxemia sobreagregada $\ldots \ldots \ldots \ldots \ldots, 4$ 


\author{
CUADRO 7 \\ TBC PULMONAR Y EMBARAZO \\ TRATAMIENTO QUIRURGICO PREVIO
}

Sobre 237 pacientes

Neumonectomías $\ldots \ldots \ldots \ldots \ldots$
Lobectomías $\ldots \ldots \ldots \ldots \ldots \ldots \ldots$
Plombaje $\ldots \ldots \ldots \ldots \ldots \ldots \ldots$
Toracoplastia $\ldots \ldots \ldots \ldots \ldots \ldots$
Frenicotripsia $\ldots \ldots \ldots \ldots \ldots \ldots$

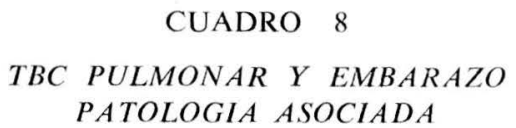

Sobre 313 casos

Casos

Anemia ............... 118

Sífilis ................. 14

Cardiopatías .............. 6

Asma ................. 1

Gastroenteritis ............ 1

Utero bicorne .............. 1

Fibromatosis uterina .......... 1

Pielonefritis $\ldots \ldots \ldots \ldots \ldots \ldots$

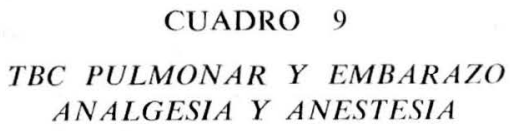

Sobre 307 partos

ACTIVAS

PRIMIGEST. 33 CASOS

ACTIVAS

MULTIGEST. 274 CASOS

INACTIVAS

$$
26
$$

$$
8
$$

- de 8 horas

8 a 24 horas

+ de 24 horas

12

$1+$

0

- de 8 horas 0

8 a 24 horas 6

+ de 24 horas 1

- de 8 horas 124

8 a 24 horas 74

+ de 24 horas 2

- de 8 horas 50

8 a 24 horas 24

+ de 24 horas 0 
CUADRO 11

TBC PULMONAR Y EMBARAZO TERMINACION EMBARAZO

Sobre 313 casos

\begin{tabular}{|c|c|c|}
\hline & Casos & Mortalidad .. \\
\hline Espontáneos & 265 & Morbilidad \\
\hline Forceps .. & 28 & Anexitis post-partum . . . . . . \\
\hline Cesáreas .. & 9 & Flebitis $\ldots \ldots \ldots$ \\
\hline Otros $\ldots \ldots$ & 5 & Retención restos placentarios $\ldots$. \\
\hline $\begin{array}{l}\text { (Versión interna, extracción podá- } \\
\text { lica, etc.). }\end{array}$ & & $\begin{array}{l}\text { Anemia } \ldots \ldots \ldots \ldots \ldots \ldots \ldots \\
\text { (Hemorragia post-partum) }\end{array}$ \\
\hline Abortos & 6 & Sicosis puerperal \\
\hline
\end{tabular}

TBC PULMONAR Y EMBARAZO MORBI-MORTALIDAD MATERNA

Sobre 313 casos

CUADRO 13

TBC PULMONAR Y EMBARAZO

MORTALIDAD FETAL

Sobre 307 partos

(Gemelares 7)

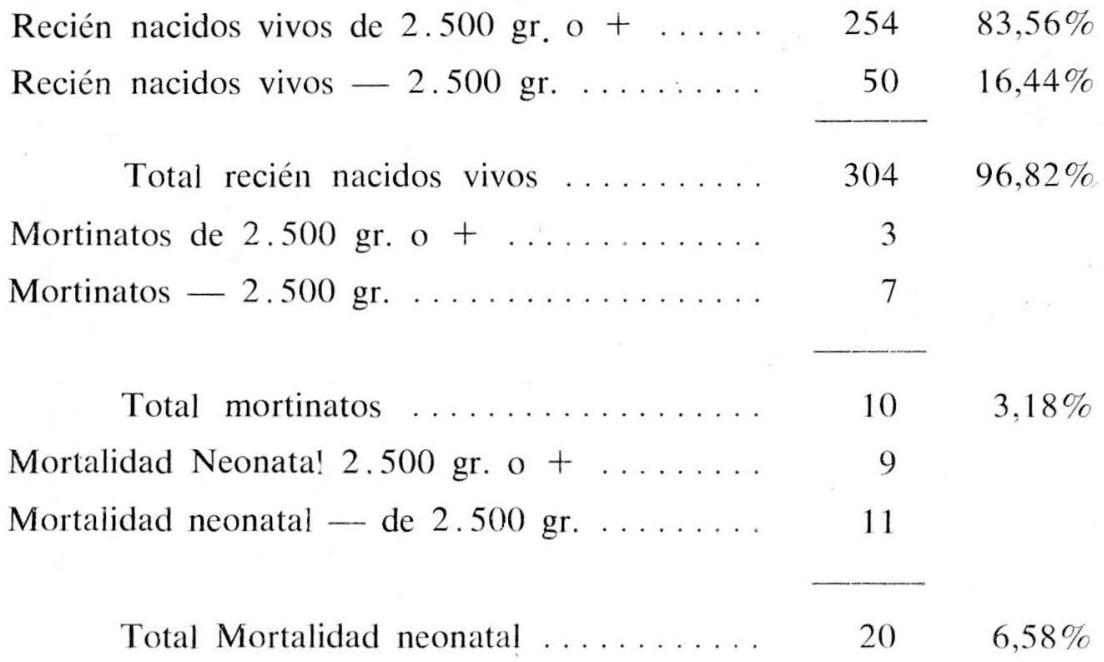


CUADRO 14

TBC PULMONAR Y EMBARAZO

EVOLUCION DE LA TBC A LA PRIMERA CONSULTA PRENATAL

Sobre 237 pacientes

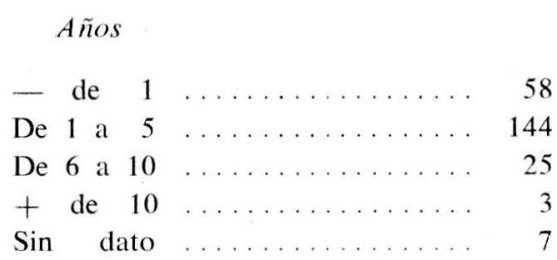

CUADRO 15

TBC PULMONAR Y EMBARAZO

TRATAMIENTO ANTES DEL PARTO

Sobre 237 pacientes

Sin tratamiento

Años

- de 1 .............. 154

De 1 a $5 \quad \ldots \ldots \ldots \ldots \ldots \ldots .63$

+ de $5 \ldots \ldots \ldots \ldots \ldots \ldots \ldots$

Sin dato .............. 3

* Ingresan en trabajo de parto. Sin control prenatal, ni en dispensario.

\section{CUADRO 16 \\ TBC PULMONAR Y EMBARAZO \\ CLASIFICACION DE TBC \\ (INTERNACIONAL)}

185 pacientes con un caso obstétrico

Diagnóstico en la primera consulta prenatal

Act.

Av. $\quad 76$

75

Mod. 75

63

Min.

31

Sin lesión 3

(Operadas)

TOTAL 185

Inac.

Est.

Estado después del puerperio

Av. = Avanzada. Mod. = Moderada. Mn. = Mínima.

Act. = Activa. Inac. = Inactiva .

Est. $=$ Estacionaria. Mej. $=$ Mejoría. Agr. $=$ Agravación. 


\author{
CUADRO 17 \\ TBC PULMONAR Y EMBARAZO \\ CLASIFICACION DE TBC \\ (INTERNACIONAL)
}

52 pacientes con casos obstétricos de repetición

Primer Caso

Diagnóstico en la primera consulta prenatal
Estado después del puerperio

$\begin{array}{crrrrrr} & & \text { Act. } & \text { Inac. } & \text { Est. } & \text { Mej. } & \text { Agr. } \\ \text { Av. } & 21 & 21 & - & 19 & 2 & - \\ \text { Mod. } & 16 & 15 & 1 & 14 & 2 & - \\ \text { Mn. } & 14 & 2 & 12 & 14 & - & - \\ \text { Sin lesión } & 1 & - & 1 & 1 & - & - \\ \text { (Operada) } & - & - & -14 & 48 & 4 & 0\end{array}$

31 pacientes sin modificaciones en posteriores casos.

21 pacientes con modificaciones en posteriores casos.

\title{
MODIFICACIONES
}

\begin{tabular}{|c|c|c|c|c|c|c|}
\hline Pacientes de & 2 casos & De 3 & De 4 & De 5 & & \\
\hline Agr. & 4 & - & — & - & $=$ & 4 \\
\hline Mej. & 11 & 3 & 1 & 2 & $=$ & 17 \\
\hline TOTAL & 15 & 3 & 1 & 2 & $=$ & 21 \\
\hline
\end{tabular}

Av. = Avanzada. Mod. = Moderada. Mn. = Mínima.

Act. = Activa. Inac. = Inactiva.

Est. = Estacionaria. Mej. = Mejoría. Agr. = Agravación

\section{BIBLIOGRAFIA}

1. BLANK B.: Tuberculosis genital y estado grávido puerperal. Prensa Méd. Argent., 50: 3165, 1963.

2. AMAYA-LEON H., VERGARA T., VILLARREAL M. J. y col.: Tuberculosis genital femenina. Rev. Colomb. Obst. Ginec. XV: 111, 1964.

3. SELIKOFF I. J., DORFMAN H. L., GUTTMACHER A. F.: Active management of pulmonary tuberculosis in pregnancy. J. Mt. Sinai Hosp., 23: $550,1956$. 
4. BICKERSTAFF H. J., COMSTOCK G. W., BURKE M. H., Routine antenatal chest X-ray findings in patientes drawn from currently surveyed population. Am. J. Obst. Gynec., 61: 41, 1951.

5. SCHAEFFER G., BIRNBAUM S. J., DOUGLAS R. G.: Present day treatment of tuberculosis and pregnancy. JAMA, 165: 2163, 1957.

6. REID D. E., CATON W. L.: Medical complications of pregnancy. $G y-$ necology and Obstetrics (Davis-Carter), v. I. Cap. 9, p. 23, W. F. Prior Co., 1953.

7. DONALD I: Practical obstetric problems. The Year-Book Publishers, Inc., London, p. 88, 1955.

8. SCHAEFFER G.: Tuberculosis in obstetrics and gynecology. Little, Brown and Co., Boston, 1956.

9. SKOM J. H., GERBIE A. B.: Management of pulmonary tuberculosis and pregnancy. Medical Clinics of North America, v. 45, p. 127, 1961.

10. FALLS F. H.: Tuberculosis y embarazo. Tuberculosis clínica. Salvat., T. II, p. 613, 1942.

11. COHEN J. D., PATTON E. A., BADGER T. L.: Am. Rev. Tuberc., 65: $1,1952$.

12. THOMAS G. W.: Pregnancy and tuberculosis Canad. M. A. J. 81: 710, 1959.

13. ROSEMBACH L. M., GANGEMI C. R.: Tuberculosis and pregnancy JAMA, 161: $1035,1956$.

14. JENTGENS H.: Tratamiento de la tuberculosis durante el embarazo, parto y puerperio. Geburtsh. u. Frauenh., 19: 99, 1959.

15. AMAYA-LEON H.: Tuberculosis en ginecología. Rev. Colomb. Obsi., Ginec., I: 227, 1950.

16. AMAYA-LEON H., VERGARA T. R., VILLARREAL M. J.: Tuberculosis genital femenina. Esquema de Terapia Médica. Res. de Comunic., IV Congreso Mundial de Ginec. y Obst., Ed. Med. Panam., 1964.

17. AMAYA-LEON H.: Hidrazida del ácido isonicotínico en el tratamiento de enfermas tuberculosas embarazadas. Rev. Colom. Obst. Ginec., V: 5, 1953.

18. LOWE C. R.: Congenital defects among children born to women under supervision of treatment for pulmonary TBC. Brit. J. Prev. Soc. Med., 18: 14, 1964.

19. CORNER G. W. NESBITT R. E. L.: Pregnancy and pulmonary resection. Am. J. Obst. Gynec., 68: 903, 1954.

20. SCHAEFFER G., EPSTEIN H. H.: Lobectomy for pulmonary tuber. culosis during Pregnancy. Am. J. Obst. Gynec., 64: 188, 1952.

21. FOLSOME C. E.: Pregnancy following major thoracic surgery for tuberculosis. Am. J. Obst. Gynec., 65: 1319, 1953.

22. LAROS N.: Noderl. Tijdschr. geneesk., 102: 264, 1958. Cit. GREENHILL: Year-Book, Obst. Gynec., 77, 1958-1959. 
23. SCHAEFFER G., BRANDER J. H.: Pregnancy following major thoracic operation. Am. J. Obst. Gynec., 92: 901, 1965.

24. BLAKE J. M.: Pregnancy with tuberculosis. Management and prognosis. New York State J. Med., 50: 2536, 1950.

25. RIST E.: Tuberculosis. Brit. M. J., 2: 247, 1927.

26. HEDVALl E.: Embarazo y tuberculosis. Acta Med. Scandinav., 147: 286, 1953.

27. SCHAEFFER G., DOUGLAS G., DRESISHPOON I. H.: The Obstetrics management of the tuberculous patient. Obst and Gynec., I: 245, 1953.

28. SZALAY G. LEHOOSKY A.: Tuberculosis pulmonar y su tratamiento durante el embarazo y post-parto. Tuberk. Arzt., XV: 622, 1961.

\section{CONGRESO INTERNACIONAL DE CITOLOGIA}

ORGANIZADO POR LA ACADEMIA INTERNACIONAL DE CITOLOGIA

\section{CON EL CONCURSO DE LA SOCIEDAD AMERICANA DE CITOLOGIA, Y}

\section{SOCIEDAD BRASILEÑA DE CITOLOGIA}

Este Congreso se llevará a cabo en la ciudad de Río de Janeiro del 19 al 22 de Mayo de 1968

Tendrá lugar en el Hotel COPACABANA PALACE

Las informaciones deben solicitarse a la Secretaría de la Comisión

Organizadora: Emilio Berla 47, Apto. 302

$$
\text { COPACABANA - RIO DE JANEIRO }
$$

Presidente: CLARICE A. FERREIRA 